\title{
Ian T. Jackson: Colossus of Craniofacial Surgery
}

\author{
Ramesh K. Sharma ${ }^{1}$ \\ ${ }^{1}$ Department of Plastic Surgery, Postgraduate Institute of Medical \\ Education and Research, Chandigarh, India
}

Indian J Plast Surg:2021;54:4-7.

Life is not important except in the impact that it has on other lives.

-Jackie Robinson

It was March 1987. For the first time in history, India had the proud privilege of hosting the World Congress of the International Confederation of Plastic Reconstructive and Aesthetic Surgery. Despite the presence of a galaxy of international stalwarts, it was Ian T. Jackson who undoubtedly stole the thunder with his outstanding presentations on the reconstruction of the orbit following resection of tumors and neurofibromatosis. To add to this, his work on craniomaxillofacial trauma, hypertelorism, and craniosynostosis received tremendous appreciation.

This visit heralded a long and fruitful association between Dr. Jackson and the Indian plastic surgery fraternity. He became a familiar figure in the annual meetings of the plastic surgery and was often the lead faculty at various operative workshops on craniofacial surgery and esthetic surgery. Over the next 15 years, he visited India on more than 20 occasions and left an indelible impression on the Indian plastic surgery scene. His work sparked interest in hitherto unexplored areas and inspired young plastic surgeons to explore newer vistas. Countless numbers of Indian plastic surgeons made a beeline to his hospital at Southfield in the United States to get insight in person into the latest in plastic surgery. He welcomed visitors from India and took great trouble to make their visits fruitful. This umbilical cord has remained as strong as ever.

He was an excellent clinician, as well as a dedicated researcher. Academically inclined throughout his career, he was a prolific author and a teacher par excellence. What stood out though, was his humanitarian attributes. In a word, he was perhaps a true karmayogi.

\section{Early Life and Academic Career}

Ian T. Jackson was born in Glasgow, United Kingdom, on December 24, 1934 (-Fig. 1). He was educated at Eastbank

published online February 15, 2021
DOI https://doi.org/

10.1055/s-0040-1721871

ISSN 0970-0358.
Address for correspondence Ramesh Sharma, MS, MCh, Diplomate National Board (Plastic Surgery), Department of Plastic Surgery, Postgraduate Institute of Medical Education and Research, Chandigarh, 160012, India (e-mail: drsharmark@gmail.com).

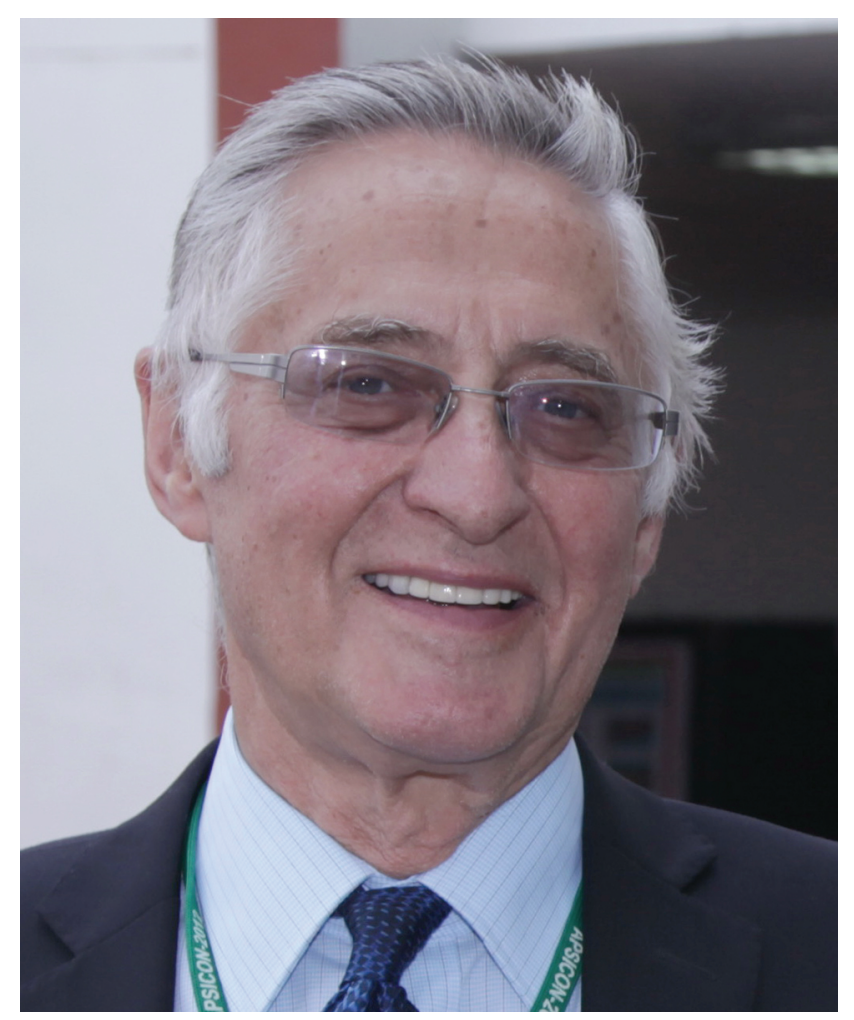

Fig. 1 Ian T. Jackson (1934- 2020).

Academy in Shettleston where he met Marjorie, who later became his wife. He earned his medical degree in Glasgow, Scotland, and completed his plastic surgery training in the West of Scotland Plastic and Maxillofacial Unit at Canniesburn Hospital. Dr. Jackson was also trained in pathology and general surgery. He was appointed as a consultant in plastic surgery at Canniesburn Hospital in 1969. Dr. Jackson was a versatile surgeon who tried to explore newer techniques to expand the boundaries of plastic surgery. He was fascinated by the discovery of the deltopectoral flap that had revolutionized the reconstruction in the head and neck region. He extended the use of this flap not

\section{(C) 2021. Association of Plastic Surgeons of India.}

This is an open access article published by Thieme under the terms of the Creative Commons Attribution-NonDerivative-NonCommercial-License, permitting copying and reproduction so long as the original work is given appropriate credit. Contents may not be used for commercial purposes, or adapted, remixed, transformed or built upon. (https://creativecommons.org/licenses/by-nc-nd/4.0/).

Thieme Medical and Scientific Publishers Pvt. Ltd. A-12, 2nd Floor, Sector 2, Noida-201301 UP, India 
only in the head and neck region but also in resurfacing of the hand defects. Dr. Jackson and his team first described the Groin flap along with its anatomical basis in 1972. The groin flap soon became a workhorse of hand surgery. He had a special interest in facial clefts and craniofacial anomalies and described numerous techniques to improve the outcome in these difficult cases. He is especially known for the primary use of the buccal myomucosal flap in cleft palate management. He championed the use of primary alveolar bone grafts in infants. He also described the sphincter pharyngoplasty for velopharyngeal dysfunction. He had a keen interest in skull base surgery and described many innovative approaches for accessing tumors and other lesions deep in the craniofacial skeleton and skull base. He was instrumental in popularizing the use of cranial bone graft in reconstruction of posttraumatic and posttumor excision reconstruction in the craniofacial region. He is especially credited for describing the disassembly approach for deep seated skull base tumors. He had a great interest in vascular malformations especially of the craniofacial region. He was also an accomplished rhinoplasty surgeon and conducted many workshops in India to demystify the art and science of esthetic rhinoplasty.

In 1979, he moved to Mayo Clinic, Rochester, as the Chief of Plastic Surgery. He established a Research Fellowship, as well as a Clinical Fellowship at Mayo, which attracted a lot of budding surgeons from across the world. His pioneering work had attracted a huge caseload of patients with craniofacial anomalies and skull base tumors. In 1982, he coauthored the monumental "Atlas of Craniomaxillofacial Surgery," which soon became a reference book for craniofacial surgery. Another of his equally famous treatise, "Local flaps in Head and Neck reconstruction" was published in 1985. This hugely popular book set the benchmark for reconstructive options in the head and neck region. The book had many reprints, and a second edition was published in 2007. He took over the editorship of the "European Journal of Plastic Surgery" in 1986 and continued as the editor for over 3 decades! Apart from this, he also edited "Plastic Surgery Outlook," and it is a tribute to his academic and scholarly credentials that he was a much sought after member of the editorial boards of more than 20 journals, including Perspectives in Plastic surgery, Indian Journal of Plastic Surgery, Quarterly Journal of Surgical Sciences Banaras Hindu University, Plastic and Reconstructive Surgery, PRS online, Journal of Ophthalmic Plastic and Reconstructive Surgery, and Journal of Computer Aided Surgery. He published close to 400 articles in peer-reviewed international journals and contributed numerous chapters in many books.

In 1989, he moved to Southfield in the United States and established a Craniofacial Institute at the Providence Hospital, which soon became a must visit center for students of craniofacial surgery. The institute had a comprehensive cleft and craniofacial team that included a pediatric neurosurgeon, oral surgeon, and orthodontist, pediatrician, an ophthalmologist, and a child psychologist. He also had an in-house computer workstation with state of the art three-dimensional (3D) computer planning software. The institute also boasted of a well-equipped research laboratory where a considerable amount of basic research was done. These research areas included intrauterine surgery in the sheep, expansion of the pedicles of myocutaneous flaps, study of bone generation in skull defects, and prefabrication of flaps. Dr. Jackson and his team were instrumental in describing the blood supply of the scalp and described the anatomical basis of the frontogaleal and occipitogaleal flaps, which have now become standard flaps in skull base surgery. The center has now been renamed after him as "Ian Jackson Craniofacial and Cleft Clinic" with a motto "we do not change a face, we change a life."

\section{My Mentor}

As a young lecturer in plastic surgery in 1987, in the Department of Plastic surgery at the Postgraduate Institute of Medical Education and Research (PGIMER), Chandigarh, I was mesmerized by the surgical teachings and operative techniques of Dr. Jackson and harbored a wish to visit and learn from him. This desire was fulfilled when I was selected for a 1-year World Health Organization (WHO) fellowship in craniofacial surgery under his tutelage in 1993. He was an indefatigable worker starting his day early morning at $5.30 \mathrm{a} . \mathrm{m}$. and work through the day until past midnight. When Dr. Jackson was not in the operation room, he was busy seeing patients in the outpatient clinic. This was very efficiently managed by his wife Mrs. Marjorie. Dr. Jackson was a very patient listener and would give a lot of attention to the patients' point of view. His bedside manners and demeanors were immaculate. Inside the operating room, he was a master craftsman and would be in complete control of the situation. He was a great teacher and would explain and demonstrate the essential operative steps to the trainees. There were always several observers in his operating room (OR) but he remembered everyone by name and ensured that all of them understood the steps of the surgery well. His meticulous technique and precise execution made the steps look deceptively simple and the procedure itself seem much quicker than expected. In all this, he made sure to communicate the progress of the surgery to patient's attenders regularly

At fortnightly, a combined meeting of the cleft and craniofacial teams took place where all the aspects of patient care were discussed, and a comprehensive plan of action was outlined for each patient including the surgical, nursing, medical, and psychosocial aspects of the management.

I still recall with extreme fondness, some of the weekends spent in his house where Mrs. Marjorie played an excellent host and would often load us with goodies for rest of the week. ( - Figs. $\mathbf{2}$ and $\mathbf{3}$ )

For me, the takeaways from this fruitful period of my life were:

- His thorough understanding and clarity of the procedure to be performed beforehand and then extreme precision and swiftness of execution on the operating table.

- His compassion and empathy for patients.

- His unruffled attitude and maintaining his equanimity despite the stressful work that he performed. 


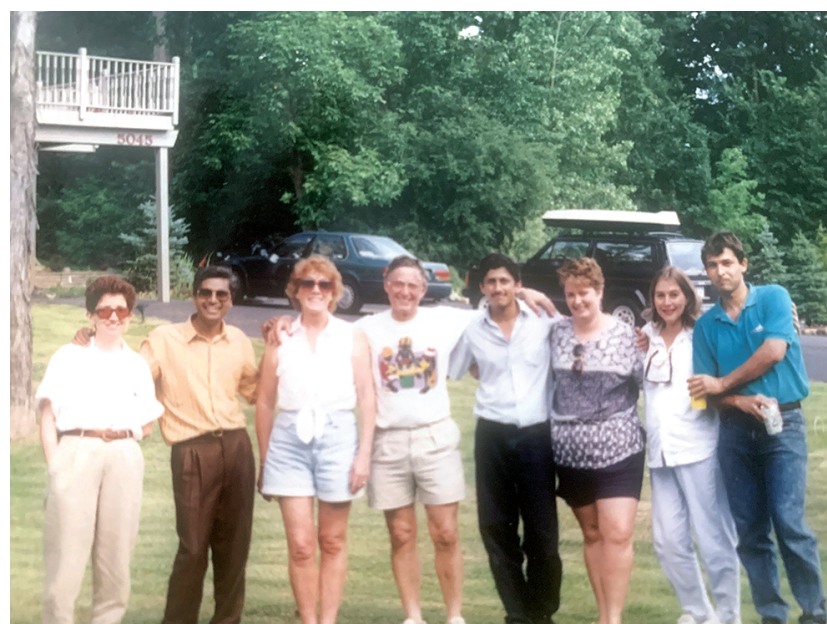

Fig. 2 Fun times at his residence over the weekend 1993.

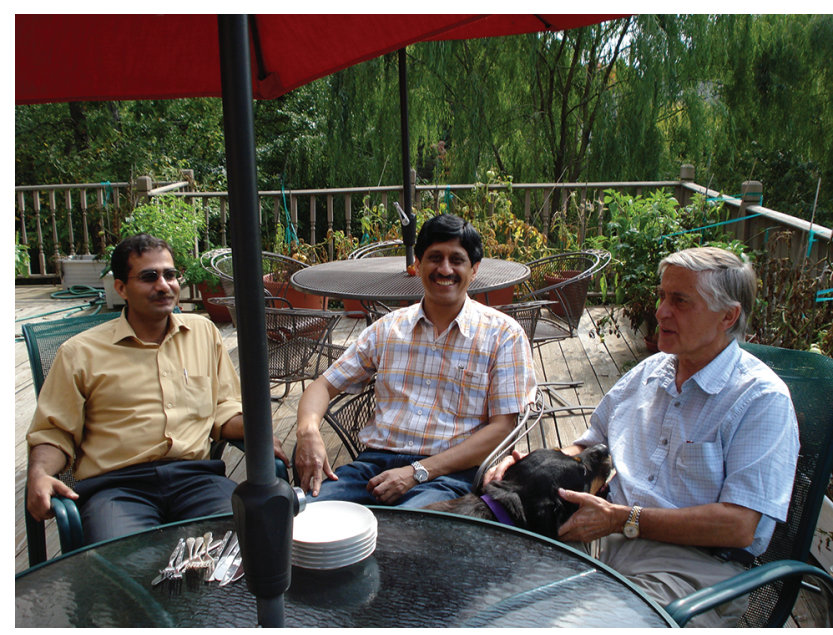

Fig. 3 Meeting Dr. Jackson at his residence 2008.

- His interest in the career and progress of his trainees and fellows long after they had left for their countries.

\section{The Indian Connection}

His love for India was legendary and he was largely instrumental in firmly establishing craniofacial surgery as a subspecialty in this country. When I returned after completing my fellowship in 1994, Dr. Jackson and his clinical nurse, Barbra Beal gifted me a plating set and a box of instruments that would help in establishing the unit back home in Chandigarh. He kept in touch with the CEO (chief executive officer) of my hospital to ensure that adequate funds and space were allotted for establishing the services in my hospital. With his blessing and encouragement, we did our first case of frontoorbital advancement at PGI in 1995. In a quarter century since, we have successfully performed more than 2,000 craniofacial surgeries in our unit. He was a regular visitor to our department on his numerous trips to Chandigarh and was happy with the progress made in the establishment of craniofacial surgery at the institute. (-Figs. $4, \mathbf{5})$. He was the star attraction when we conducted the annual meeting of the

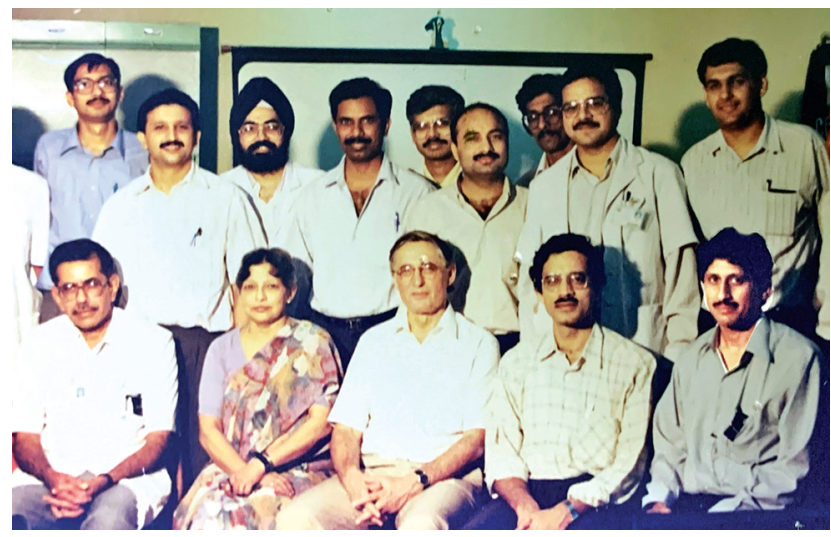

Fig. 4 Dr. Jackson with the faculty and residents of the department of Plastic Surgery in 1996.

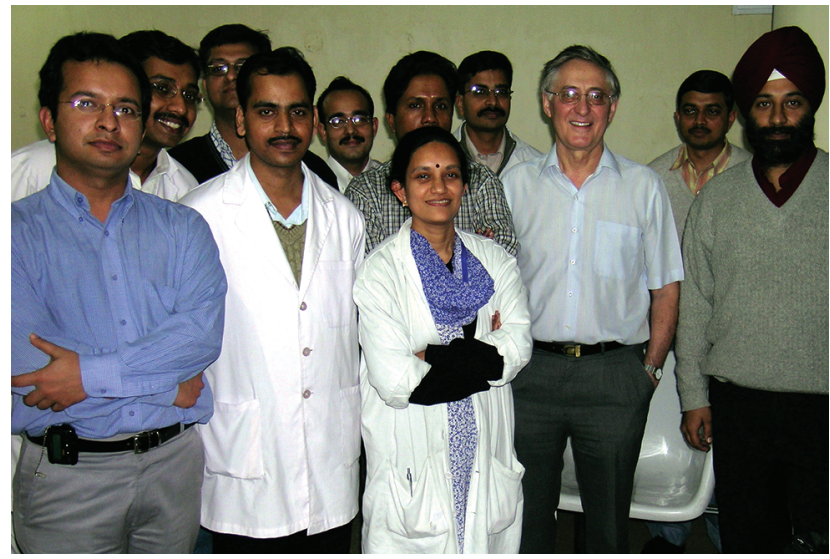

Fig. 5 Residents of the department after a teaching session in 2002.

Indian Society of Cleft Lip Palate and Craniofacial Anomalies in 2007 (-Fig. 6). We also had the pleasure and the honor of having him operate at the PGIMER. The most memorable part was his postsurgery interaction with the residents, wherein he would not only answer questions related to surgery but would also encourage them to be inquisitive and accept the challenges in life.

He was invited as a visiting professor and operating faculty in many surgical workshops in many cities in India, including New Delhi, Mumbai, Ahmadabad, Chandigarh, Chennai, Bangalore, and Pune. An entire generation of plastic surgical trainees in the 1990 to 2010 period knew him and were influenced by his teaching skills and philosophy. He was hugely popular not only in India but across the globe and his teachings and surgical techniques have influenced the lives of countless students and patients alike.

\section{Awards and Accolades}

Ian had numerous awards and honors to his credit; they include the following:

- 1992: the Clinician of the Year of American Association of Plastic Surgeons.

- 1993: Senior Visiting Professor, Plastic Surgery Educational Foundation in 1993. 


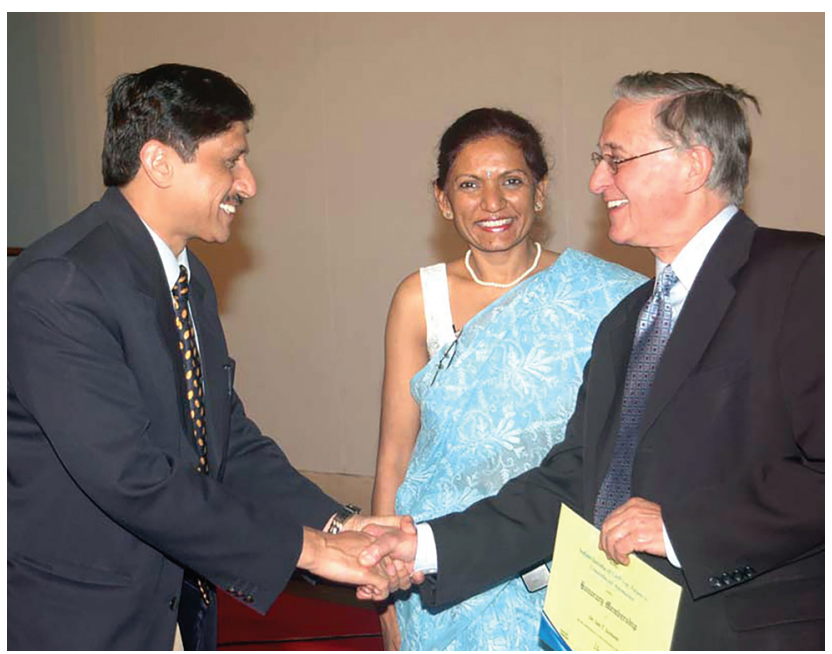

Fig. 6 Welcoming Dr. Jackson in the meeting of Indian Association of Cleft Lip, Palate, and Craniofacial Anomalies in 2007.

- 1996: Sir Harold Gillies Gold Medal by British Association of Plastic Surgeons.

- 1998: The Royal College of Surgeons of Edinburgh Medal.

- 1999: Honorary Award by the American Association of Plastic Surgeons.

He was an honorary member of 17 foreign scientific societies including Association of Plastic Surgeons of India, Association of Surgeons of India, and Indian Society of Cleft Lip Palate and Craniofacial Anomalies.

\section{A Humanitarian}

He was known around the world for his charitable work. David, a 3-year-old Peruvian child came to Prof. Jackson as a patient and was subsequently adopted into the Jackson family. This was the subject of a much-appreciated BBC (British Broadcasting Corporation) series, which gave rise to a film in 2003, The Boy David Story. Dr. Jackson was also deeply involved in international medical volunteer work and served as founding Honorary Chairman of the Smile Train, an international charitable organization that provides free corrective cleft surgery for children in 87 countries, trains overseas surgeons in craniofacial surgery, and provides hospital funding for the procedures. He was a major force in guiding the initial years of The Smile Train Inc. In a truly magnanimous but typical gesture, he had requested that there should not be any services after his death and asked that any donations should go to the "Smile Train."

\section{Association of Plastic Surgeons of India Award}

The Association of Plastic Surgeons of India (APSI) have instituted an award called "PGIMER IT Jackson Cleft and Craniofacial Award" given every year to encourage the surgeons who are doing exemplary work in this field. A complete session is devoted to the memory of Dr. Jackson during the annual meeting of the APSI. This is our humble tribute to this wonderful multifaceted personality. He was not only a great plastic surgeon and an inquisitive researcher but also an extraordinary human being and an amazingly effective motivator. Dr. Jackson truly dedicated his life to advancing plastic surgery, helping people with facial deformities and clefts, educating three generations, and hundreds of plastic surgeons across the world.

The last couple of years had been tough for the great old man. Marjorie, his better half was a constant companion by his side throughout. We were in constant touch with her all through this tough time. The August 2, 2020, the day he left us, will always be simultaneously sad and memorable for me as it also happens to be my birthday. Ian is survived by his loving wife Marjorie, his three daughters, two sons, and grandchildren.

He was a man who walked the talk-one who preached what he practiced.

Such great persons never die, they continue to live and spread happiness through their good work. His innumerable students and admirers would ensure that his legacy continues.

Let us continue to follow the path shown by him.

"It may be that I shall find it good to get outside of my body-to cast it off like a disused garment. But I shall not cease to work! I shall inspire men everywhere.

\section{Swami Vivekananda}

\section{Conflict of Interest}

None declared. 